\title{
Structure and physical properties of the polar
}

\section{oxysulfide CaZnOS.}

Timothy Sambrook, Catherine F. Smura and Simon J. Clarke*

Department of Chemistry, University of Oxford, Inorganic Chemistry Laboratory, South Parks Road, Oxford, OX1 3QR, UK.

Kang Min Ok

Department of Chemistry, University of Oxford, Chemistry Research Laboratory, University of Oxford, Oxford, OX1 3TA, UK

P. Shiv Halasyamani

Department of Chemistry, University of Houston, 136 Fleming Building, Houston, TX 77204-5003, USA

\section{Supporting Information}

E-mail: $\quad$ simon.clarke@chem.ox.ac.uk

Fax: $\quad+441865272690$

Tel: $\quad+441865272600$ 
Figure S1. Optical absorbance spectrum of CaZnOS.

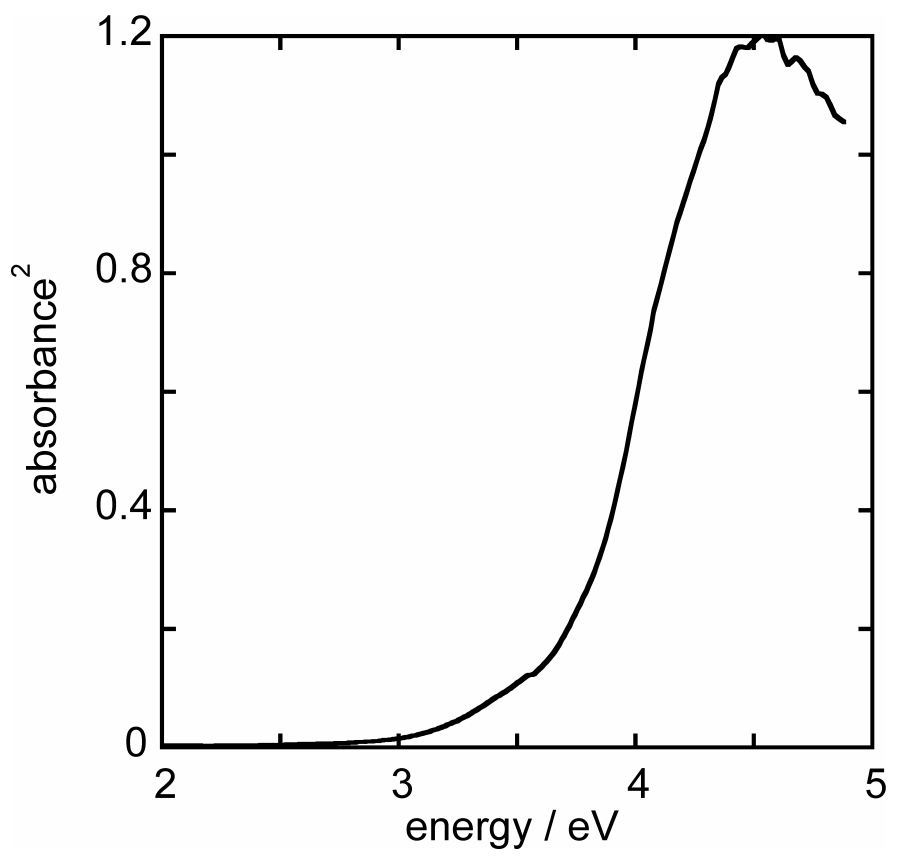


Figure S2. (a) Room temperature electrical polarization of CaZnOS. (b) The electrical polarization of $\mathrm{CaZnOS}$ at $4 \mathrm{kVcm}^{-1}$ as a function of temperature.

(a)

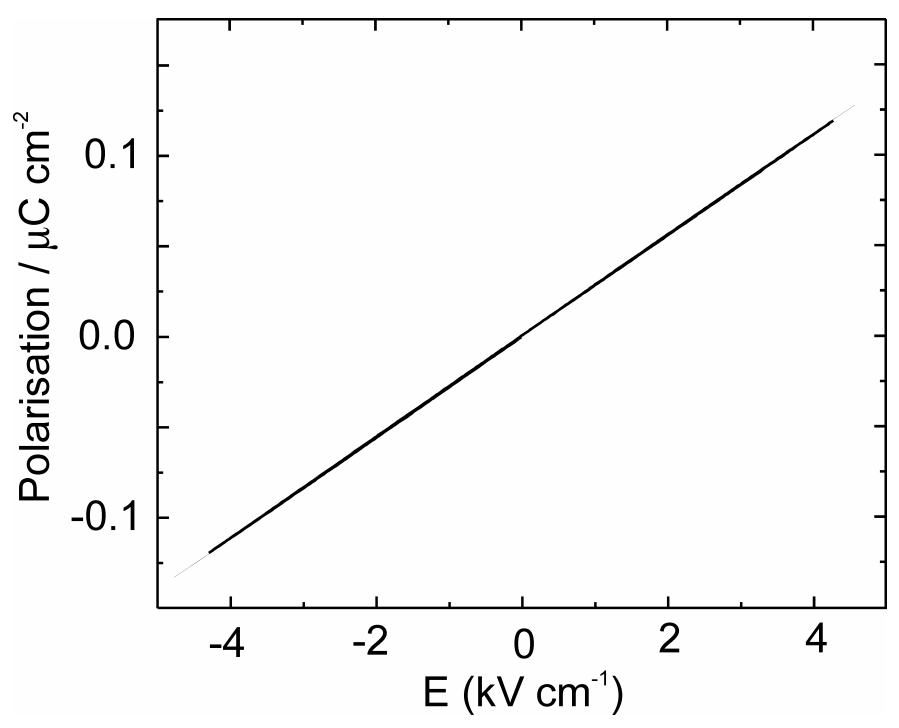

(b)

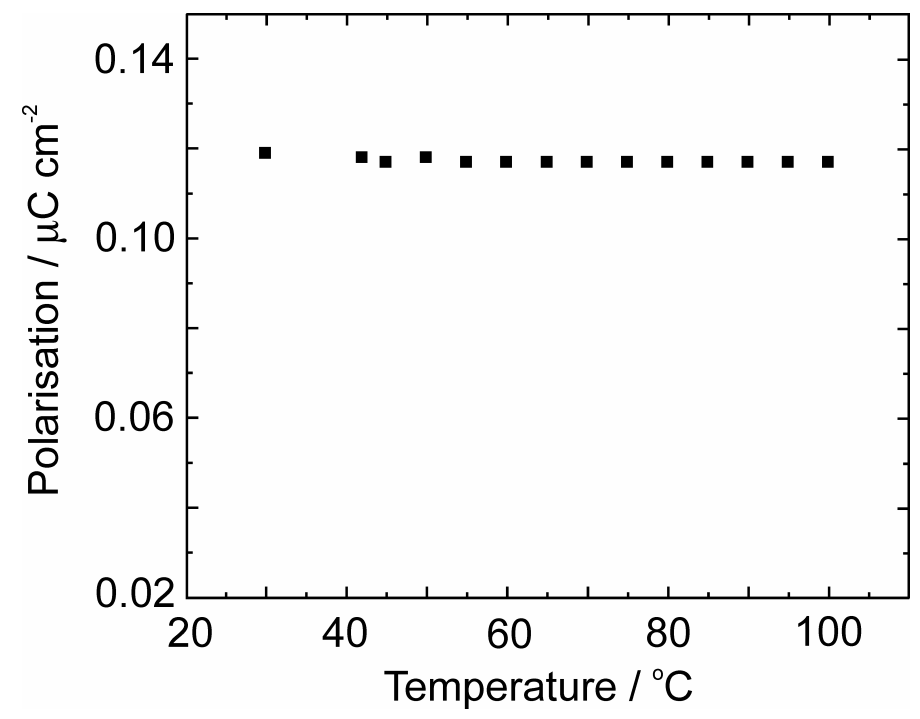

